\title{
IX.
}

Eine Beobachtung über das Entfcehn des. holländifchen Torfs.

Aus einem Briefe des Dr. M. vas Manum in Harlein an FaUjas - SAIYT-FoND. *)

Harlem den rfien Januar rgoz.

Seitdem man durch rine genauere Únierfuchung des Torfs der Moorgründe fich ibbrzeúgt hat, dafs diefer aus kerftörten Stengeln, Blättern, Wurzeln und andern Pflanzentheilen befteht, und rafs die holländifchen Torfbrüche, (und fo auch die in andern Ländern,) nach ihrer Lage und ihrem Vorkommen in mehrem Schichten in hoch lingenden Moräften zu urtheilen, nicht durch Wafferfluthen dihin gefchwemmt feyn können, fondern firh noch an der Stelle befinden, wo fie entftanden find; ift bäulig die Prage geive $\int_{e n}$, aus welcher Pflanze denn eigentlich der Torf entftehe. Znfällig habe ich im Jalıre $1>89$ einé B́eobachtung gerracht, die mir über diele Frage viel Licht zu verbreiten fcheint. Zum mindeftep lernen wir durch fie einige Planzen kennen, aus welchen Torf in fehr kurzer Zeit an. wachlen kann.

In einem Garten univcit Ifarlem hatte ich 1784 ein kleines i Fufs tiefes Balin graben lalfen, um

*) Annales du Mufeum d' Hijtoire naturelle, T. 2, p. 9 r.

d. $H$.

$\mathrm{Kk} 2$ 


\section{[ 508 ]}

darin chineflche Goldfifche zu halten. Der Boden war hier nichts weniger als moraftig, hatte lange Zeit uber 5 Fufs tief zur Kultur von Pflanzen gedient, und beftand zu unterft aus bläulichem Sande. Die Wände diefes Baffins wurden, um Feftigkeit zu erhalten, ringsum mit Holz bekleidet.

Schon in Jahre 1796 merkte $i c h$, dafs das Baffin viel an Tiefe verloren habe, ohne den Grund aufzufinden. Ich nahm darin in Anfange einige Wafferplanzen wahr, die fich fehr fchnell vermehrten, und es oft fo ausfüllten, dafs ich fie mulste wegnehmen laflen, um den Fifchen melir Raum za verfchaffen, und fie fichtbar zu machen. Diefe Pflanzen wurden immer zaillreicher, und zugleich verminderte fich die Tiefe des Baffins immer mehr.

Im Jahre $17 \delta 9$ wurdo mein Garten durch eine Springthuth überfchweinmt, die fo viel Schlamm in das Baffin fpülte, dafs ich mich genüthigt fah, es ausfchöpfen und ron Schlamm reinigen zu laffen. Ich hatte den Arbeitern befohlen, es ja bis auf den Grund zu reinigen, und war daher nicht wenig verwundert, als fie fertig waren, das Balfin nur 6 Fufs tief zu finden. Sie behaupteten, es könne nicht tiefer gewefen feyn, weil he bis auf den feften Boden gekommen wăren; da ich aber beftimmt das Gegentheil wufste, fo wies ich fie an, es weiter auszugraben, bis fre auf den bläulichen Sand gekommen feyn würden, der den Boden des Baffins ausmachte. Kunm hatten fe diefe Arbeit angefaigen, fo merkte ich, dafs fich eine $4 \mathrm{Fufs}$ mächtige Lage Torf in dem Baffin gebildet haben müfe. Getrocknet, 


\section{[ 509$]$}

brannte diefer Torf wie anderer und gáb diefelbea Koblen. Ich zeigte ihn mehrern, die Kenntnifs vom Torfwefen hatten.

Diefes wirklich bewundernswardige Erejgnifs verdient um fo mehr Aufmerklamkeit, als jch zugleich Gelegenheit gebabt habe, zu bomerken, aus welchen Pflanzen diefer-Torf entfanden war. Während der ganzen Zeit, dafs der Torf Gch im Baffin anhaufte, habe ich darin faft keice andere Pfanze wahrgenommen, als die lange Bach-Conferve, (Conferva rivularis,) und den Walfer-Federball, (Myriophyllum fpicarum.) Zwar ftanden einige andre Pfanzen am Rande des Baf́ns, doch nur in fo geringer Menge, dafs fie höchftens aufserft wenig zur Bildung der Torflage können beigetragen baben.

Nachdem das Baffin gereingt und wieder ausgegraben ift, habe ich darin keine Bach-Conferve weiter wahrgenommen; dagegen nahm das Myrio phyllum fpicatum darin fa iberhand, dafs ich es mebrmahls in einem Jabre mulste fortnebmen laffen. Auch jetzt nohro zwar die Tiefo des Baflos,ab, dach nicht fo fchnell wie das orfte Mahl. Begierig, zu wiffen, ob fich otwa aofs neue wieder Torf gebildet habe, liels ich das Balfon im Jabro 179.5 ausfchöpfen; os enthielt aber kelnen Torf, fondern sur Schlamro, welcher in allem vollkommen dem glich, der fich goworbnlich in ftehonden Gewälera aus vermodernden Wallerpllanzen bildet.

Diefo Beobachtung, verglichos mit der varigen, zeigt uns, dafs dio Conferve die Hauptphanzo ift, aus der der Torf, der fich in Itehonden Ges 


\section{[ $\begin{array}{lll}510 & ]\end{array}$}

wälfern bildet, entfteht. Frägt man; was wohl die Conferve gefchickter als andre Pflanzen machen durfte, den Torf zu erzeugen, fo fcheint mir diefes zum Theil davon abzuhängen, dals diefe Conferve nicht leicht fault, wie das die Beobachtungen des Botanikers Meefe und anderer beweifen. Es Icheint überdies, die Conferve wercle gegen den Herbft fpecififch fchwerer, daher fie fich in den Waftern zu Boden fenkt, und zugleich die andern Waflerplanzen, zwilchen denen fie fich befindet, mit. hinab zieht. Endlich läfst fich aus meinen beiden Beobachtungen fchliefsen, dafs die Conferve die Eigenfchaft habe, auch die andern Pllanzen; welche fie umgiebt, zum Theil gegen die Verwefung zu fchützen; denn das Myriophyllum fpicatum war im erften Falle erhalten, im andern aber, als die Conferve nicht mehr mit demfelben wuchs, verweft.")

*) Noch eine Eigen[chaft, we]che die Conferve zur Bildung fo fclmell wachfenden Torfes vorziiglich gefchiclit maclıt, ift die aufserordentliche Schnelligkeit, mit der fie, nach Vau cher's Beolachtung, fich durch die von ihm bemerkten Camenähnlichen Körnchen fortpflanzt. Die von einer einfachen fadenförmigen Graben - Conferve aufgefammelten, dem blofsen Auge kaum fichtbaren Kürnchen hatten fich fchon innerhalb dreier Monate zu Pflanzen entwickelt, die felbft mit reifen Körnchen verfehn waren, fo dafs in einem Baffin; welches immer mit Waffer verfehn iff, jährlich 2 bis 3 Generationen diefer Conferve zum Vor[cheine kommen könnten. Erft wuchs aus dem. Körnchen ein feiner Faden hervor; bald rerfchlangen fich viele folcher ein- 